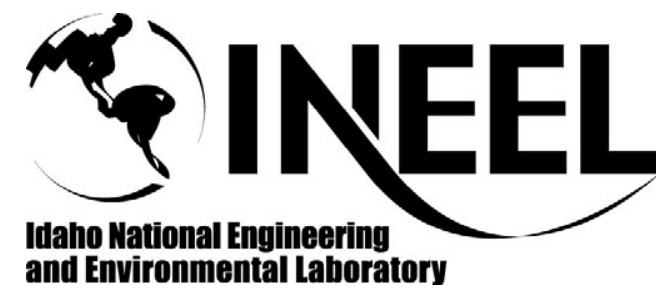

Idaho National Engineering and Environmental Laboratory
INEEL/CON-04-01751

PREPRINT

A Systems Engineering Framework for Design, Construction and Operation of the Next Generation Nuclear Plant

\author{
Edward J. Gorski \\ Charles V. Park \\ Finis H. Southworth
}

June $21-26,2004$

INCOSE 2004 - Systems Engineering, Managing Complexity and Change

This is a preprint of a paper intended for publication in a journal or proceedings. Since changes may be made before publication, this preprint should not be cited or reproduced without permission of the author.

This document was prepared as a account of work sponsored by an agency of the United States Government. Neither the United States Government nor any agency thereof, or any of their employees, makes any warranty, expressed or implied, or assumes any legal liability or responsibility for any third party's use, or the results of such use, of any information, apparatus, product or process disclosed in this report, or represents that its use by such third party would not infringe privately owned rights. The views expressed in this paper are not necessarily those of the U.S. Government or the sponsoring agency. 


\title{
A Systems Engineering Framework for Design, Construction and Operation of the Next Generation Nuclear Plant
}

\author{
Edward J. Gorski, Charles V. Park, Finis H. Southworth \\ Idaho National Engineering and Environmental Laboratory \\ 2525 N. Fremont Avenue / P.O. Box 1625 \\ Idaho Falls, ID 83415-3750
}

\begin{abstract}
Not since the International Space Station has a project of such wide participation been proposed for the United States. Ten countries, the European Union, universities, Department of Energy (DOE) laboratories, and industry will participate in the research and development, design, construction and/or operation of the fourth generation of nuclear power plants with a demonstration reactor to be built at a DOE site and operational by the middle of the next decade. This reactor will be like no other. The Next Generation Nuclear Plant (NGNP) will be passively safe, economical, highly efficient, modular, proliferation resistant, and sustainable. In addition to electrical generation, the NGNP will demonstrate efficient and cost effective generation of hydrogen to support the President's Hydrogen Initiative.
\end{abstract}

To effectively manage this multi-organizational and technologically complex project, systems engineering techniques and processes will be used extensively to ensure delivery of the final product. The technological and organizational challenges are complex. Research and development activities are required, material standards require development, hydrogen production, storage and infrastructure requirements are not well developed, and the Nuclear Regulatory Commission may further define risk-informed/performance-based approach to licensing. Detailed design and development will be challenged by the vast cultural and institutional differences across the participants. Systems engineering processes must bring the technological and organizational complexity together to ensure successful product delivery. This paper will define the framework for application of systems engineering to this $\$ 1.5 \mathrm{~B}-\$ 1.9 \mathrm{~B}$ project.

\section{Introduction}

To meet future world energy needs, ten countries - Argentina, Brazil, Canada, France, Japan, the Republic of Korea, the Republic of South Africa, Switzerland, the United Kingdom, and the United States - have agreed on a framework for international cooperation in research for an advanced generation of nuclear energy systems known as Generation IV. These ten countries have joined together to form the Generation IV International Forum (GIF) to develop futuregeneration nuclear energy systems that can be licensed, constructed, and operated in a manner that will provide competitively priced and reliable energy products while satisfactorily addressing nuclear safety, waste, proliferation, and public perception concerns. The objective of 
Generation IV is to provide nuclear energy systems for international deployment before the year 2030, when many of the world's currently operating nuclear plants will be at or near the end of their operating licenses.

\section{Background}

In 2001, the GIF agreed to proceed with development of a technology roadmap for Generation IV nuclear energy systems. The purpose of the Generation IV roadmap is to identify the most promising nuclear energy systems (consisting of both a reactor and a fuel cycle) for meeting the challenges of sustainability, safety and reliability, economics, and proliferation resistance and physical protection.

The GIF used more than 100 experts from the ten countries to evaluate more than 100 Generation IV nuclear energy system concepts proposed by the worldwide research and development (R\&D) community. The Generation IV roadmap process culminated in the selection of six of the most promising Generation IV systems for further development. The motivation for the selection of six systems was to:

- Identify systems that make significant advances toward the technology goals

- Ensure that Generation IV adequately addresses the important missions of electricity generation, hydrogen and process heat production, and actinide management

- Provide some overlapping coverage of capabilities, because not all of the systems may ultimately be viable or attain their performance objectives and attract commercial deployment

- Accommodate the range of national priorities and interests of the GIF countries.

\section{Goals for Generation IV}

To guide the Generation IV review and selection process, the GIF established a set of goals for the new reactor systems. These goals have three purposes. First, they served as the basis for developing criteria to assess and compare the systems in the technology roadmap. Second, they are challenging and stimulate the search for innovative nuclear energy systems-both fuel cycles and reactor technologies. Third, they serve to motivate and guide the R\&D on Generation IV systems. The GIF defined eight goals in the four broad areas of sustainability, economics, safety and reliability, and proliferation resistance and physical protection. The requirements for the NGNP that are identified here are based on the Generation IV goals.

\section{Selection of the VHTR: An Innovative Concept for Electricity and Hydrogen Production}

A major driving force for the Generation IV roadmap was the recognition that in the coming decades, energy demand in the United States, other industrialized countries, and the entire world will escalate considerably beyond current supply capabilities. This increased energy demand will require the development of new energy sources and the upgrading of the world's energy infrastructure. Meeting future energy requirements by simply expanding today's mix of

production options will not address concerns about potential adverse environmental impacts or 
the need for cost-effective, reliable, and sustainable energy sources. While nuclear power can play an important role in filling future energy needs, the GIF recognized that new and innovative reactor designs would be required to realize the full benefits of nuclear power as a source for production of both electrical power and hydrogen (for transportation and industrial uses).

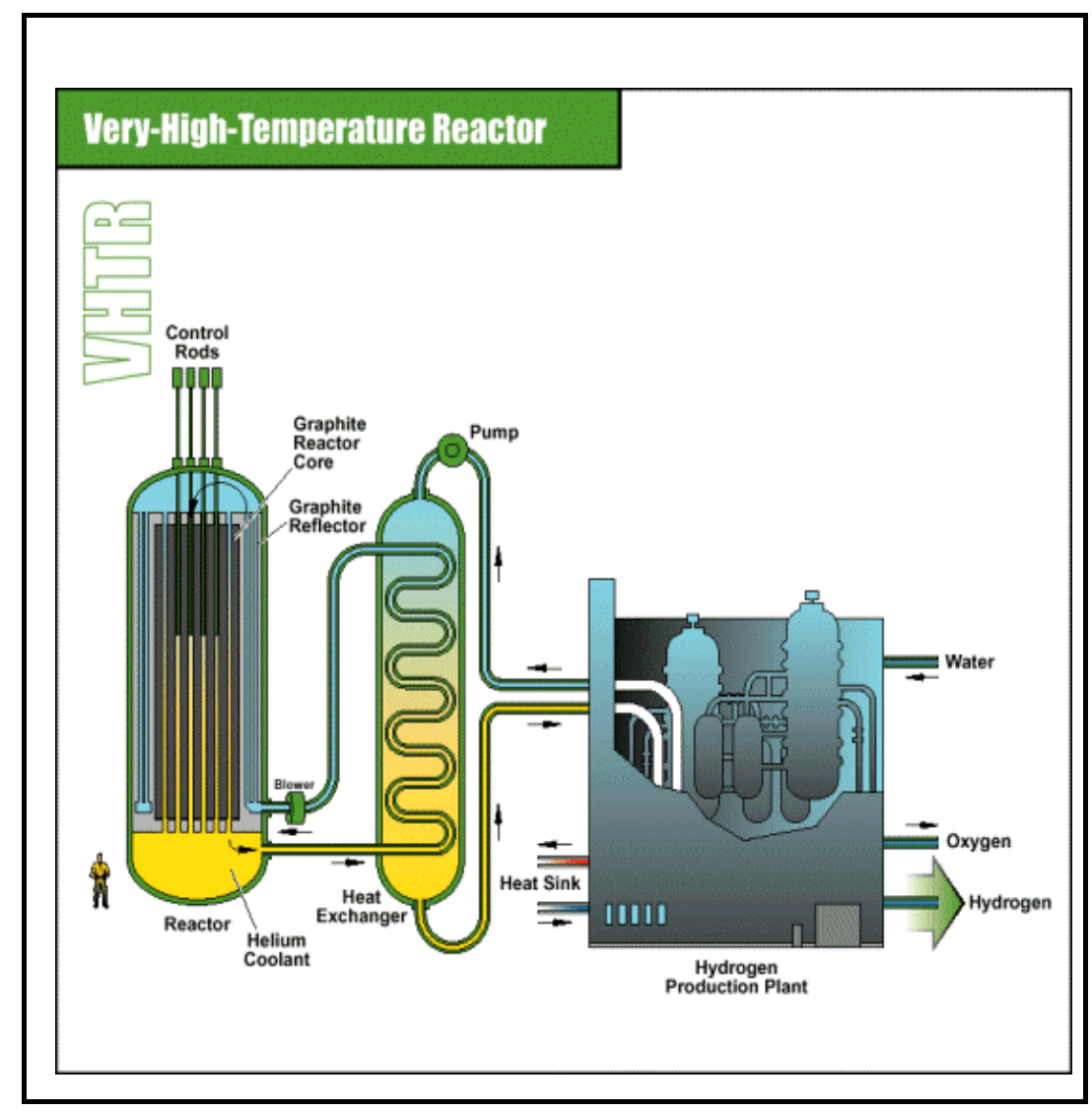

\section{Next Generation Nuclear Plant Mission}

The primary mission for the NGNP is to demonstrate nuclear reactor assisted cogeneration of electricity and hydrogen while meeting the Generation IV goals for safety and reliability, sustainability, proliferation resistance and physical security and economics. As a demonstration project, NGNP design, development, and deployment will aid in revitalizing nuclear energy infrastructure vital to support the growing demand for electricity while providing hydrogen needed to fuel emission-free vehicles. Thus NGNP will reenergize the domestic nuclear and transportation industries by:

- Demonstrating advanced power and hydrogen generation technologies

- Demonstrating the safety capabilities of the NGNP concept

- Achieving NRC licensing of a next generation reactor

- Resolving and sharing technology risks to restart our energy infrastructure

- Eliminating 'first-of-a-kind' concerns/issues using a risk-based methodology

- Demonstrating an operable design that ensures natural passive safety 
- Providing high efficiency electricity and process heat for demonstrating and optimizing hydrogen production

- Supporting the development and testing of prototype hydrogen infrastructures necessary for new transportation energy sources and other existing and new industrial hydrogen applications.

For the United States, the next phase in the Generation IV nuclear energy system development process is to proceed with preconceptual studies for the NGNP. Innovation continues to be a major focus of this phase of the program, but with the constraint that the technologies employed are consistent with completion of the NGNP reactor licensing and construction process by 2016 - 2019 timeframe. Of the six most promising Generation IV nuclear energy systems identified in the Generation IV roadmap, the helium-cooled VHTR was identified as the nearest-term concept (capable of meeting the target date) that also has the capability to efficiently produce hydrogen.

\section{Foundation Established - The Framework Begins}

The INEEL was named the lead laboratory for nuclear reactor technology by the Secretary of Energy in 2002. This decision was based on the extensive INEEL experience developing 50+ reactors in the last 50+ years. With the foundation laid by the GIF for a Very High Temperature Reactor and the President's Hydrogen Initiative with a goal of hydrogen production in the next decade, the INEEL took the lead to develop an initial set of functions and requirements for the proposed Next Generation Nuclear Plant. The following figure depicts the functions to be performed and the highest-level requirements to be met by such a project.

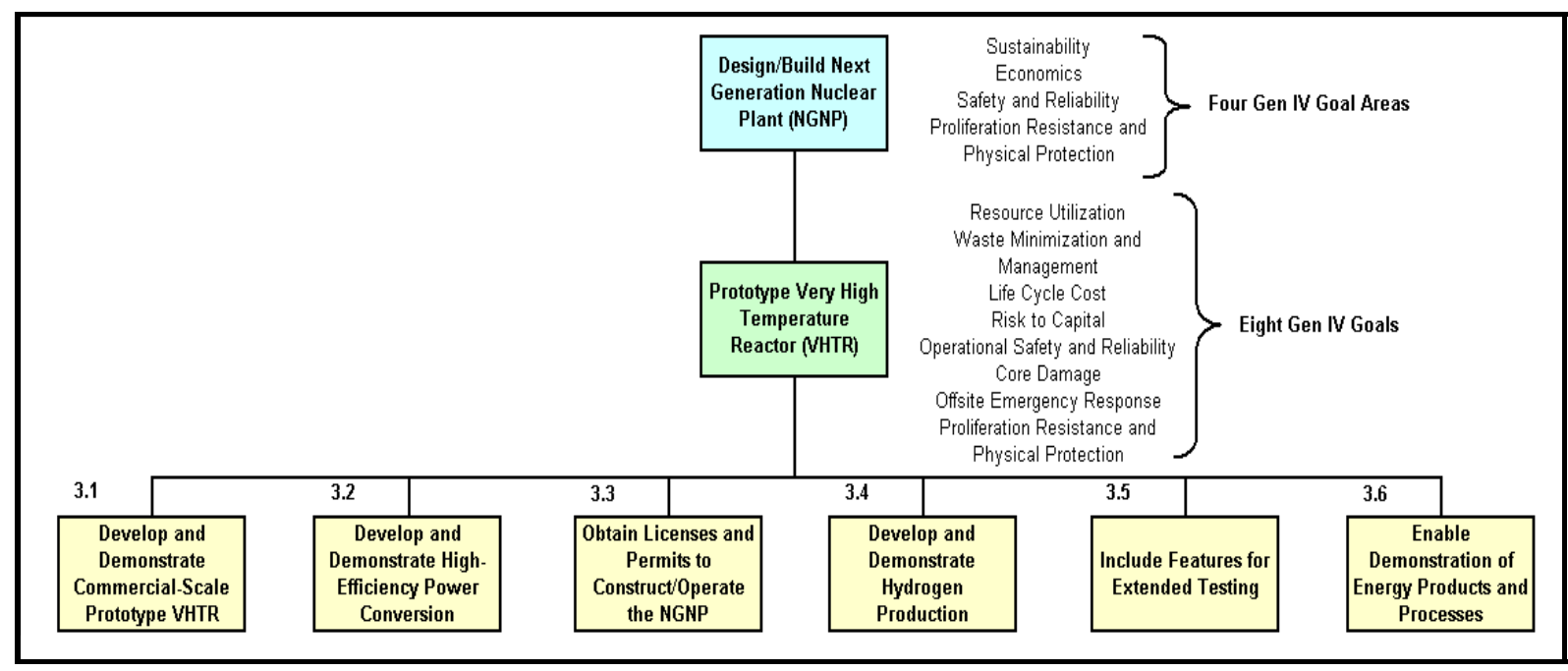

\section{NGNP Project Functions}

Further decomposition of the requirements provides a descriptive view of the NGNP project as perceived prior to preconceptual studies or conceptual design. It focuses on the following 
high-level NGNP functions:

- Develop and demonstrate a commercial-scale prototype VHTR

- Develop and demonstrate high efficiency power conversion

- Obtain licenses and permits to construct/operate the NGNP

- Develop and demonstrate hydrogen production

- Include provisions for future testing

- Enable demonstration of energy products and processes.

Develop and Demonstrate a Commercial-Scale Prototype VHTR. A commercial-scale prototype of a VHTR with a pebble-bed or prismatic core design will be built, tested, and operated to demonstrate the performance characteristics of future advanced high-temperature reactors. The prototype VHTR is called the NGNP. The primary function of this prototype plant will be to demonstrate both operational and safety performance of high-temperature reactors over a range of normal and transient conditions. This demonstration phase will include an extended startup test program to confirm various aspects of the licensing bases for this first-of-a-kind reactor concept. Specific objectives of this phase will include plant operation and control during startup and shutdown, and under full- and part-load conditions. Fuel, coolant, and safety system performance will also be evaluated to address proposed inspections, tests, analyses, and acceptance criteria that would apply to the licensing of future high-temperature nuclear power plants under 10 CFR 52 (Code of Federal Regulations). Because of the nature of an extended testing program, the NGNP will likely include instrumentation and other design features that would not necessarily be included in follow-on commercial nuclear plants. The NGNP will demonstrate the ability to generate process heat in an efficient and reliable manner.

Develop and Demonstrate High-Efficiency Power Conversion. The NGNP will be equipped with a high-temperature Brayton cycle power conversion system to deliver electric power to the electric grid. The primary function of this power conversion system is to demonstrate the ability of a VHTR to produce low-cost electricity, using high-temperature gas-turbine technology in an efficient and reliable manner.

Obtain Licenses and Permits to Construct/Operate the NGNP. In accordance with the Energy Reorganization Act of 1974, the NGNP will be licensed by the Nuclear Regulatory Commission (NRC) under 10 CFR 50 or 10 CFR 52, for the purpose of demonstrating the suitability of a VHTR for commercial electric power and hydrogen production applications. As a first-of-a-kind reactor combined with a hydrogen production plant, the technical issues will be substantial and licensing will include remobilization of the NRC for licensing reactor activities. The licensing of the NGNP by NRC will also demonstrate the effectiveness of licensing future advanced high-temperature reactors for commercial applications. It is anticipated that many of the current issues associated with NRC licensing of a non-LWR and the use of nuclear power for hydrogen production will be resolved during the licensing of the NGNP. The licensing of the NGNP by NRC should contribute to the stabilization of future non-LWR licensing activities by identifying weaknesses in the licensing needs and eliminating uncertainties in the cost and schedule associated with obtaining construction and operating licenses for future nuclear plants. 
Develop and Demonstrate Hydrogen Production. Hydrogen production plant(s) will be included as part of the NGNP facility to demonstrate the capability of high-temperature reactors to produce hydrogen in a cogeneration mode and demonstrate hydrogen production. Hydrogen production will be demonstrated using high-temperature water electrolysis and a thermochemical process. Fifty megawatts-thermal (MWt) of the plant energy will be available for producing hydrogen in a cogeneration mode. The intent of this demonstration phase is to verify hydrogen production efficiencies and evaluate hydrogen system operation and control. Interface issues, including system interactions, instrumentation and control, and safety features (barriers and isolation features), will also be evaluated.

Include Provisions for Future Testing. The NGNP will include provisions for conducting future test programs after the initial licensing and demonstration test program is complete. The intent of these provisions is to provide sufficient design flexibility to ensure that future research and development missions are not precluded by unnecessary system design constraints. Examples of future testing programs that should be considered in developing the preconceptual designs for the NGNP include: testing programs to evaluate plant safety and performance margins, assessment of proposed investment protection concepts, training programs, evaluation of advanced control room designs, and development and testing of advanced instrumentation and control systems. The tests could also cover a range of normal operating conditions, transient conditions, and specified accident conditions, that would provide data needed for hightemperature reactors (with similar safety features) to meet the NRC design certification requirements of 10 CFR 52.47 .

\section{Requirements Validation}

To ensure that the objectives of the GIF were met by the defined functions and requirements generated by the INEEL, a matrix was developed to map each of the lower level NGNP requirements to the objectives defined by the GIF. The Functions and Requirements document was released at Revision 0 (Ryskamp). Industry participation and review/comment cycles were exhaustive with major comments suggesting any particular architecture be left open.

A independent review of the functions and requirements document is also being conducted to ensure that the correct functions have been identified and the requirements are "necessary and sufficient" at this level of the decomposition. Once validated and independently reviewed, the functions and requirements will be used to generate a specification and procurement to be open to industry bid for a preconceptual design of the NGNP.

The current NGNP Program is divided into three projects. The first project addresses the long lead-time work for nuclear fuel development and qualification project (Feltus). The nuclear fuel for this reactor is designed to self-contain radioactive isotopes to reduce contamination and reduce the potential for proliferation. The fuel will also be instrumental in meeting requirements for passive safety.

The second project is for the design, construction, and operation of the hydrogen production plant project. As a user of process heat and/or electrical power, the project is independent of the 
reactor. However, integration of the two plants will be important for safe operation.

The third project relates to the materials $R \& D$ needs. Since some materials are new to the high-temperature environment, extensive $R \& D$ efforts are required to meet these requirements with eventual certification by standards organizations such as the American Society of Mechanical Engineers (ASME) and others.

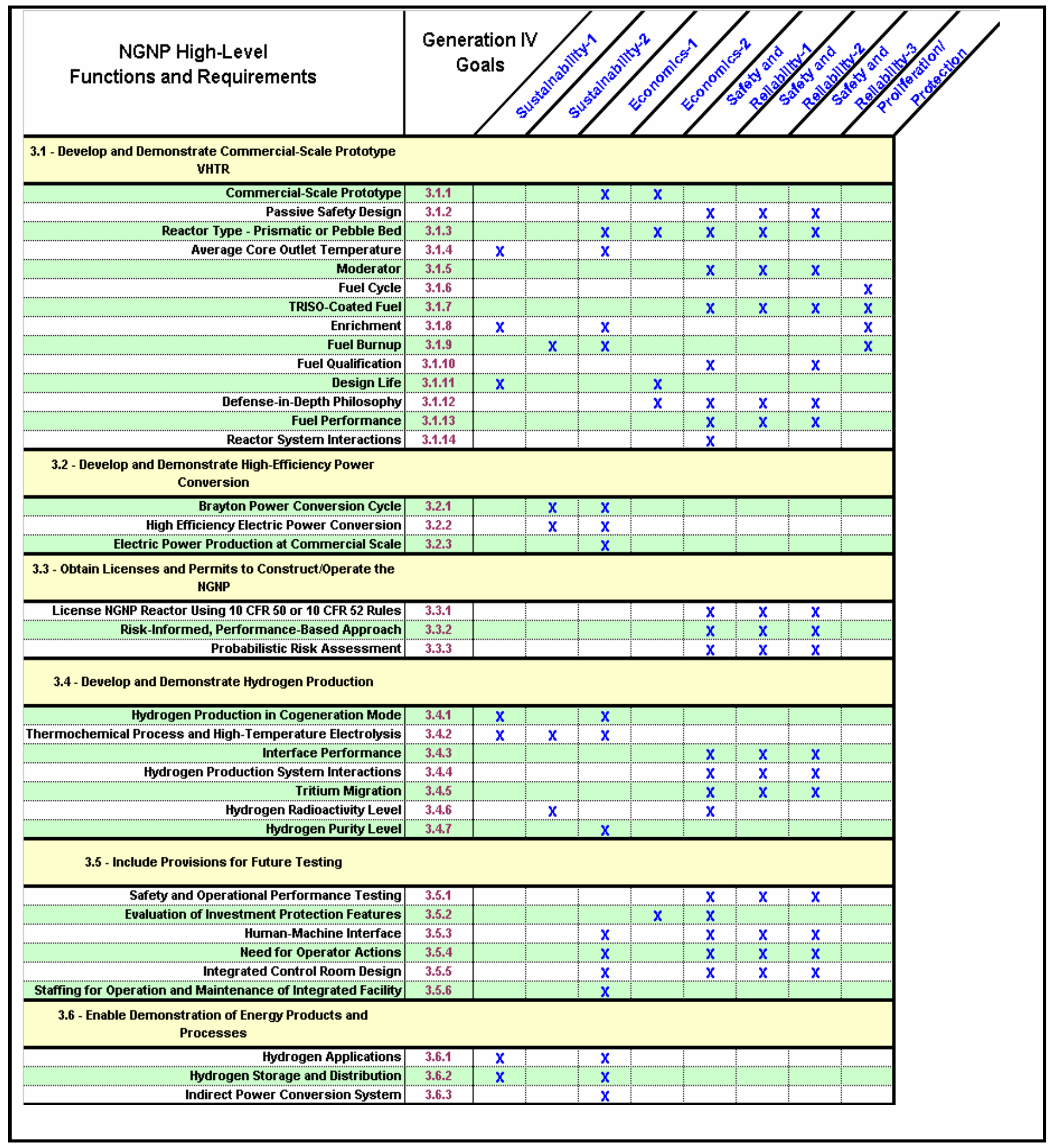




\section{NGNP Design, Construct and Operate Vision}

The Program organization structure is designed to allow autonomy and encourage cooperation. The Program consists of government, industry, universities and international partners operating as a single program activity with seamless management and execution. Research and development focuses on nuclear fuels and high-temperature materials research as well as power conversion and hydrogen production. The NGNP Program will leverage the international initiatives of the GIF and NERAC subcommittees and attract the best researchers in the key disciplines for reactor and hydrogen applications.

The draft high-level project logic chart depicted below outlines a predecisional structure of the NGNP program and projects.

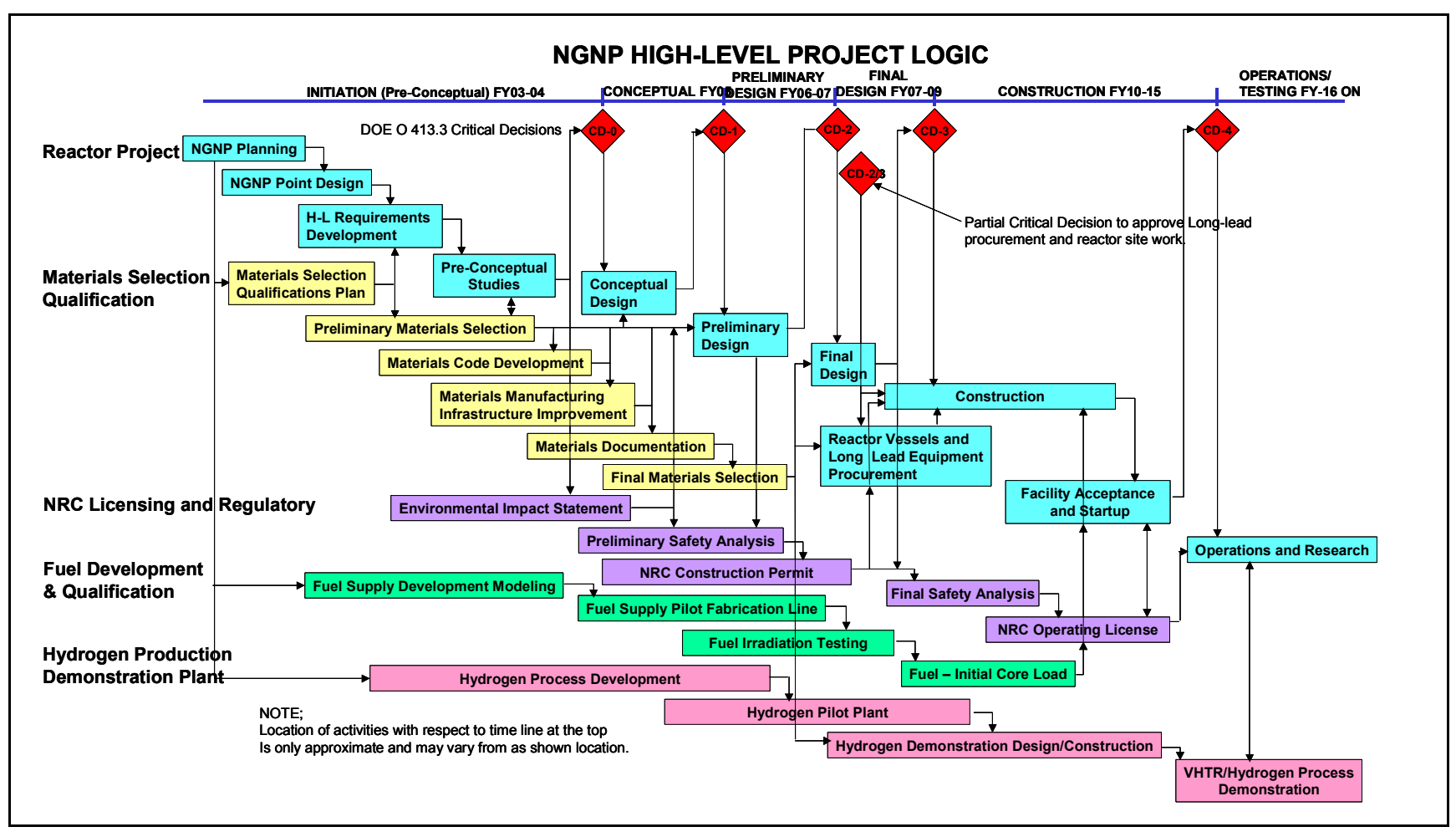

The following summarizes the systems engineering approach for the Next Generation Nuclear Plant:

- Creation of seamless management: one program - government, industry, universities and international partners

$\circ$ Operate NGNP as a single program activity with seamless management and execution

- Collaborate on research and development, and share findings while protecting intellectual property

- Take maximum advantage of standard tools to enable inter-participant collaboration. 
- Focus on advanced NGNP development

○ Focus on fuels and high-temperature materials research

- Utilize full-system, component, or scenario simulations

- Validate simulations by rigorous correlation with constrained experiments and archival data

- Create problem-solving environments

$\circ$ Provide NGNP development support

○ Ensure state-of-the-art collaboration tools

- Develop laboratory-computing environment

- Encourage strategic alliances and collaboration

- Leverage international initiatives, GIF, NERAC subcommittees

- Collaborate with the best R\&D programs of other DOE laboratories, other agencies, universities, industry, and foreign participants

- Attract the best researchers in the key disciplines for reactor and hydrogen applications.

\section{The Energy Bill}

The 2004 Energy Bill now before Congress in rewritten form includes funding for the Next Generation Nuclear Plant and anticipates cost-shared partnerships with domestic industry or international participants for research, development, design, construction, and operation of the research facility (NGNP), and preference in determining the final project structure shall be given to an overall project which retains United States leadership while maximizing cost sharing opportunities and minimizing Federal funding responsibilities. The draft energy bill specifically addresses international collaboration with the GIF countries, the Russian Federation, or other international partners where such specialists or facilities provide access to cost-effective and relevant skills or test capabilities.

The Energy Bill originally released from conference in mid-November 2003 and passed by the House shortly thereafter was stalled in the Senate in late 2003. The Bill was rewritten in early 2004 with some funding cuts for the overall nuclear program. The Bill still includes language for both the new reactor and hydrogen production. Since the NGNP is not an official DOE project until passage of the Energy Bill, further definition of the project at this point in time is predecisional only.

A draft Program Management Plan has been developed. In addition, a draft Project Execution Plan has been written. The Hydrogen Plant Project has also developed a draft Project Execution Plan.

A Systems Engineering Management Plan (SEMP) at the program level will be developed in the future. The SEMP will concentrate on collaboration, integration, project management support, and a systems engineering toolbox. 


\section{References}

Feltus, M. A., et al, Technical Program Plan for the Advanced Gas Reactor Fuel Development and Qualification Program, Oak Ridge National Laboratory, ORNL/TM-2002/262, April 2003.

Ryskamp, J. M., et al, Next Generation Nuclear Plant - High-Level Functions and Requirements, INEEL/EXT-03-01163, Rev. 0, September 2003.

U.S. Department of Energy Nuclear Energy Research Advisory Committee and the Generation IV International Forum, A Technology Roadmap for Generation IV Nuclear Energy Systems, GIF-002-00, December 2002, http://gif.inel.gov/roadmap/.

\section{Biography}

\section{Finis H. Southworth}

Finis H. Southworth is the department manager of Systems and Decision Science. He provides system science \& analysis, decision analysis, and systems integration for R\&D at the INEEL. He is the U. S. Product Manager for the Very High Temperature Gas Cooled Reactor for the U.S. Department Of Energy; he provides program management for development, design, and construction of this Generation IV reactor system. Previously, Finis served as Technical Director of the Generation IV Gas Cooled Reactor Systems Technical Working Group. Finis is also serving as INEEL Program Manager for the Advanced Gas Reactor Fuel Development and Qualification Program.

Before coming to the INEEL, Finis was the manager of systems planning for the Florida Power and Light Company where he served as a member of the CEO/Chairman of the Board's Strategic Planning Team. Finis has a Ph.D. in Nuclear Engineering Sciences from the University of Florida, and he is an Adjunct Faculty member at Idaho State University where he teaches Management of Quality and Productivity for the College of Business.

\section{Edward J. Gorski}

Edward J. Gorski is a systems engineer in the department of Systems and Decision Science at the INEEL. He provides systems engineering support to the Next Generation Nuclear Plant program and the Advanced Gas Reactor Fuel Development and Qualification Program. Previously, Edward served as systems engineer for the INEEL Spent Nuclear Fuel Program.

His prior nuclear experience includes commercial nuclear power systems engineering at the Tennessee Valley Authority nuclear plants, PSE\&G Salem and Hope Creek nuclear plants, Department of Energy Office of Environmental Management DOE Headquarters, and the National Nuclear Security Administration at the Pantex plant.

\section{Charles V. Park}

Charles V. Park is a Senior Advisory Engineer/Scientist in the department of Systems and Decision Science at the INEEL. In his current role, Charles is project manager for the hydrogen production plant project as part of the Next Generation Nuclear Plant program. 